\title{
Una revisión a la especial vulnerabilidad del menor con discapacidad
}

\section{A review about the special vulnerability of minors with disabilities}

\section{Resumen}

El presente artículo supone una breve revisión, desde un punto de vista sociojurídico, de la especial vulnerabilidad e interseccionalidad que afecta a dos colectivos de personas que, a juicio del autor, deben ser objeto de una específica protección jurídica: las personas menores de edad y las personas con discapacidad. Sobre esta especial vulnerabilidad que les diferencia de sus pares sin ella, surge la necesidad de identificar un sujeto de derecho independiente sobre el cual establecer una autónoma protección jurídica: el menor con discapacidad. Se expondrán los motivos y razonamientos socio-jurídicos que, a nuestro entender, justifican la necesidad de crear una configuración legislativa unitaria, inexistente hasta la fecha, que englobe la protección jurídica conjunta de un colectivo específico y doblemente vulnerable, y que a día de hoy tiene sus derechos reconocidos de forma dispersa, residual, e incluso inconexa, lo que dificulta el ejercicio efectivo y práctico de los mismos.

\section{Palabras clave}

Menor, discapacidad, especificidad, vulnerabilidad, interseccionalidad, diferenciación, sujetos de derecho.

\begin{abstract}
This article is a brief review, from a socio-legal point of view, of the special vulnerability and intersectionality that affects two groups of people who, according to the author, should be subject to specific legal protection: minors and people with disabilities. On this special vulnerability that differentiates them from their peers without it, the need arises to identify a subject of independent law on which to establish autonomous legal protection: the minors with disabilities. The socio-legal reasons and reasoning that, in our opinion, justify the need to create a unitary legislative configuration, nonexistent to date, that encompasses the joint legal protection of a specific and doubly vulnerable group, and that today has its rights recognized in a scattered, residual, and even disjointed way, which makes it difficult to exercise them effectively and practically.
\end{abstract}

\section{Keywords}

Children, disabilities, specificity, vulnerability, intersectionality, differentiation, legal subjects.

\author{
Pablo Díaz Domínguez \\ $<$ diazdominguezp@gmail.com> \\ Universidad de Sevilla. España
}

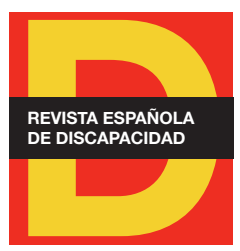

\section{Para citar:}

Díaz, P. (2021). Una revisión a la especial vulnerabilidad del menor con discapacidad. Revista Española de Discapacidad, 9(1), pp. 59-73.

Doi: <https://doi.org/10.5569/23405104.09.01.03>

Fecha de recepción: 23-11-2020 Fecha de aceptación: 29-05-2021 


\section{El menor con discapacidad como sujeto en sí mismo considerado}

Existe una serie de grupos sociales o colectivos de sujetos sobre los que, por diversas razones que se desarrollarán a continuación, los distintos ordenamientos jurídicos deben garantizar y brindar una protección jurídica más intensa, en tanto están compuestos por personas en situación de máxima vulnerabilidad (Arévalo, 2015, p. 87). Se les denomina "grupos vulnerables" (Miñarro, 2017, p. 2) y, entre ellos, podemos destacar algunos como los de los menores de edad, mujeres, migrantes, personas con discapacidad, personas refugiadas y desplazadas, etc. Estos grupos vulnerables se presentan ante la ley en situación de desventaja respecto a los demás, debido a la dificultad para hacer efectivos sus derechos en condiciones de igualdad y la exposición a unos riesgos superiores al resto de la población.

Pero la mayor vulnerabilidad no depende, ni se configura, normalmente, a través de un único factor, sino que se acentúa en la medida en que en la persona concurre dos o más, ya sean físicos o sociales, como pueden ser la edad, discapacidad, enfermedad, género, pertenencia étnico-cultural, etc. La combinación trasversal de estos factores de riesgo determina la especial vulnerabilidad de un colectivo de sujetos (Castaño et al., 2019, p. 7)

En este sentido, Lázaro (2014, p. 18), en el estudio de Unicef sobre vulnerabilidad y exclusión en la infancia, apunta que estos colectivos de mayor debilidad sobre los cuales se aúnan dos o más situaciones de vulnerabilidad deben ser objeto de una protección jurídica especial puesto que, en caso contrario, corren el riesgo de la exclusión social.

Es indudable que las personas menores de edad con discapacidad integran un grupo vulnerable o frágil al recaer en ellos más de un factor de riesgo, la minoría de edad por un lado y la discapacidad por otro, lo que les coloca en una situación de desventaja respecto a otros grupos vulnerables, razón por la cual entendemos que las normas deben dispensar una reforzada protección de sus derechos como plenos ciudadanos que son.

\subsection{La situación estadística en torno a la discapacidad}

Según la Observación General n 9 del Comité de los derechos del niño de las Naciones Unidas de 27 de febrero de 2007 (Comité de los derechos del niño, 2007), "se calcula que hay entre 500 y 650 millones de personas con discapacidad en el mundo, aproximadamente el $10 \%$ de la población mundial, y 150 millones de ellos son niños. Más del $80 \%$ vive en los países en desarrollo con acceso a los servicios escaso o nulo. La mayoría de los niños con discapacidad en los países en desarrollo no están escolarizados y son completamente analfabetos. Está reconocido que la mayor parte de las causas de la discapacidad, tales como la guerra, las enfermedades y la pobreza, se pueden prevenir, lo cual a su vez previene y/o reduce las repercusiones secundarias de las discapacidades, con frecuencia causadas por la falta de una intervención temprana u oportuna. Por consiguiente, hay que adoptar más medidas para movilizar la voluntad política necesaria y lograr un compromiso auténtico de investigar y llevar a la práctica las medidas más eficaces para prevenir las discapacidades con la participación de todas las capas de la sociedad".

1. El presente trabajo se enmarca dentro del grupo de investigación PAIDI SEJ-617 "Nuevas dinámicas del Derecho Privado Español y Comparado" (IUPRIVATUM) de la Junta de Andalucía, del que es investigadora responsable la profesora Inmaculada Vivas Tesón. 
A la luz de estas abrumadoras cifras, no parece preciso tener que justificar nuestro estudio, si bien no se trata de una cuestión de cantidad de sujetos de derechos, sino de cualidad y especial vulnerabilidad. Resulta incuestionable que un colectivo formado por, aproximadamente, 150 millones de personas en el mundo, deba contar con cuerpo normativo propio e independiente de los de otros colectivos. Sin embargo, en España no es así. Sí es cierto que el Derecho español los reconoce como sujetos derechos, si bien lo hace en legislaciones distintas y, en ocasiones, inconexas.

En nuestro país, según la Base de datos estatal de personas con discapacidad, a fecha de 31 de diciembre de 2015, se registraron un total de 195.717 personas menores de edad y con discapacidad administrativamente reconocida. A pesar de ello, y como ya se ha señalado, no son los números o las cifras los que crean la necesidad de proteger a unos sujetos de derechos, sino su especial vulnerabilidad.

A estos datos se suma un problema añadido: las dificultades que existen en la realización de estadísticas acerca de la discapacidad. A diferencia de otros colectivos de personas sobre los cuales se pueden elaborar estadísticas más exactas y precisas como, por ejemplo, el de las personas menores de edad, en materia de discapacidad se carecen de datos estadísticos oficiales.

Y ello porque, en opinión de Gosálbez (2013, p. 181), a la hora de elaborar estadísticas en el ámbito de las personas con diversidad funcional pueden darse una serie de dificultades, especialmente de carácter conceptual y terminológico, debido a que no existe una definición unitaria a nivel internacional del concepto de discapacidad, y a la existencia de subtipos dentro de la discapacidad diferentes entre sí, configurándose como un fenómeno complejo que necesita de firmes compromisos a los efectos de solventar esta problemática y poder establecer unas estadísticas fiables como punto de partida para conocer la realidad y, por consiguiente, abordar adecuadamente la protección jurídica de las personas con discapacidad.

En este sentido, ya se han adquirido ciertos compromisos, tanto a nivel internacional como nacional, que pretenden fomentar la mejora en la recopilación de los datos estadísticos atinentes a este colectivo, aunque, en nuestra opinión, no se están llevando a cabo.

La Convención sobre los derechos de las personas con discapacidad de la ONU de 2006 (en adelante, la Convención) contempla en su artículo 31 que "los Estados Partes recopilarán información adecuada, incluidos datos estadísticos y de investigación, que les permita formular y aplicar políticas, a fin de dar efecto a la presente Convención" (Naciones Unidas, 2006).

A pesar de ello, en la práctica, no se ha llevado a cabo de forma efectiva como tantos otros mandatos de la Convención. Por ejemplo, en España, a día de hoy, los únicos datos estadísticos oficiales en torno a la discapacidad son los de la Encuesta de Discapacidad, Autonomía personal y situaciones de Dependencia (conocida como EDAD) del Instituto Nacional de Estadística, publicada en noviembre de 2008, sin que existan ningunos posteriores, aunque parece que se comienzan a tomar ciertos compromisos para elaborar nuevas estadísticas. Entre ellos, destacamos el Plan Estadístico Nacional 2017-2020, aprobado por el Real Decreto 1518/2018, de 28 de diciembre, en el cual se establece el compromiso de realizar nuevas estadísticas en torno a la diversidad de capacidades mediante diversos programas, entre los que cabe destacar el Programa número 7751 para la estadística sobre discapacidad, autonomía personal y situaciones de dependencia a ejecutar en el cuatrienio 2017-2020. Si bien este no se ha materializado, el 30 de diciembre de 2020, el Consejo de Ministros aprobó el Plan Estadístico Nacional 2021-2024, mediante el Real Decreto 1110/2020, de 15 de diciembre, en el que incorpora expresamente la perspectiva de la discapacidad, junto a las de género, edad y nacionalidad, en las operaciones estadísticas en las que esta realidad sea relevante. 
Tanto Naciones Unidas como la Organización Mundial de la Salud, comienzan a incorporar entre sus recomendaciones la necesidad por parte de los Estados miembros de recopilar y mejorar las estadísticas relativas al colectivo con discapacidad, con nuevas metodologías y estrategias de encuesta, además de promover su identificación conceptual y estadística única a nivel internacional.

En esta línea, cabe destacar la Estrategia Europea sobre Discapacidad 2010-2020 (Comisión Europea, 2010), que se define como el nuevo establecimiento de una estrategia para capacitar a las personas con discapacidad para que puedan disfrutar plenamente de sus derechos y participar en la sociedad y la economía en igualdad de condiciones; y con el fin de aplicarla de la mejor forma posible, las instituciones de la Unión Europea y los Estados miembros deben trabajar juntos para mejorar los datos estadísticos.

Destacamos, asimismo, entre otras acciones dirigidas a la mejora y actualización estadística, la realizada por Eurostat (2013) mediante su Guía de la estadística en la cooperación al desarrollo de la Comisión Europea, o la de la Red Académica de Expertos Europeos en Discapacidad, que proporciona a la Comisión Europea un análisis de los datos y políticas de los Estados miembros y gestiona la base de datos DOTCOM, que efectúa el seguimiento de los instrumentos políticos relacionados con la Convención en la Unión Europea y los Estados miembros.

En conclusión, aunque a día de hoy sigan existiendo dificultades a la hora de recopilar datos estadísticos sobre personas con discapacidad, tanto en el plano nacional como internacional existe un compromiso de mejora y actualización mediante la ejecución de programas de desarrollo estadístico. Uno de los pilares básicos que promueven estos nuevos modelos de recopilación de datos es la armonización unitaria a nivel internacional e, incluso, nacional, del concepto de persona con discapacidad, puesto que ello supone el problema básico que dificulta la determinación de los encuestados y lo que provoca que los números difieran con la realidad social.

Por tanto, aunque a día de hoy se trate de datos desfasados, la única encuesta a la que podemos recurrir para encontrar datos oficiales es la ya citada Encuesta sobre Discapacidad, Autonomía personal y situaciones de Dependencia (EDAD 2008), la cual estimó que en España residían alrededor de 130.000 niños y niñas con discapacidad menores de 15 años. No se hace una estimación específica y objetiva de menores de edad, al establecer el límite de 15 años y no en 18 años, pero supone una aproximación orientativa, significando el $2 \%$ del total de niños y niñas menores de 15 años residentes en España.

\subsection{Su especial vulnerabilidad}

¿Por qué se encuentra el menor con discapacidad en situación de desventaja con respecto a los demás grupos vulnerables?

En nuestra opinión, las personas menores de edad con discapacidad son los sujetos de derecho más vulnerables en prácticamente todas las sociedades. Más aún, aunque más adelante profundizaremos, entendemos que una niña con discapacidad puede reunir una triple cualidad de vulnerabilidad (menor de edad, mujer y discapacidad) factores sobre los cuales podrían sumarse incluso más, como el factor de raza o pobreza, lo que la convierte en el eslabón más débil de la sociedad. En el citado ejemplo de mujeres y niñas con discapacidad aparece la llamada "discriminación múltiple" o "discriminación interseccional", la cual supone la conjugación de dos o más factores que interactúan al mismo tiempo y de manera conjunta sobre un indivi- 
duo, y que configuran la discriminación como agravada y compleja respecto a las personas sobre las que no sufren la intersección de dichos factores.

Si bien podría entenderse que el colectivo de sujetos de menores con discapacidad tiene sus intereses protegidos en nuestro ordenamiento jurídico a través de la aplicación conjunta de diversas normativas, por un lado, las que velan por los derechos del menor, como pueden ser, entre otras normas, el Código Civil y la Ley Orgánica 1/1996, de 15 de enero, de Protección Jurídica del Menor, de modificación parcial del Código Civil y de la Ley de Enjuiciamiento Civil, y, por otro, las que conciernen a la personas con discapacidad, entre las cuales podemos destacar el Real Decreto Legislativo 1/2013, de 29 de noviembre, por el que se aprueba el Texto Refundido de la Ley General de derechos de las personas con discapacidad y de su inclusión social o la Ley 26/2011, de 1 de agosto, de adaptación normativa a la Convención internacional sobre derechos de las personas con discapacidad, lo cierto es que su especial vulnerabilidad hace que, en nuestra opinión, sus derechos no puedan ser protegidos satisfactoriamente a través de normas independientes e, incluso, inconexas, que no contemplan la diferenciación que supone un menor con discapacidad respecto a otro sin ella, ni la de una persona adulta con discapacidad respecto a una menor de edad con capacidades diferentes.

Partiendo de lo anterior, creemos que sería necesario realizar un ejercicio de especificación o concreción del Derecho, doctrina introducida por el jurista y filósofo italiano Norberto Bobbio (1991, pp. 109-110), y en particular, su proceso evolutivo de especificación del Derecho, posteriormente identificado y desarrollado por Peces-Barba (1991, pp. 154-155), a través del cual se considere al menor con discapacidad como un sujeto de derechos independiente y en sí mismo considerado que goce de un status jurídico ad hoc que contemple concretamente su vulnerabilidad y necesidades dignas de protección jurídica.

Y ello es así debido a que la conjugación de varios factores de vulnerabilidad deriva en su mayor debilidad, indefensión o desventaja frente al resto de sujetos de derechos, provocando que sufran una singular discriminación social, así como una mayor dificultad a la hora de equiparar sus derechos a los de los demás ciudadanos. No hay duda de que la probabilidad de ser víctimas de diversas formas de abuso o maltrato es mucho más alta en los niños y las niñas con discapacidad que en sus pares sin ella, situación que se ve agravada por las dificultades que encuentran a la hora de denunciar (Berástegui y Gómez-Bengoechea, 2006, pp. 295304). Así lo hace ver Unicef (2013) en su hoja informativa titulada Niños, niñas y jóvenes con discapacidad.

De este modo, como se desprende del citado informe, desde el Fondo de las Naciones Unidas para la Infancia se identifican algunas de las causas que provocan una mayor vulneración de los derechos más básicos para los niños, niñas y jóvenes con discapacidad, la cual puede presentarse de distintas formas (violencia física, psicológica o emocional) y en diferentes ámbitos (familiares, institucionales y sociales).

Según el Informe sobre maltrato infantil en la familia en España (Centro Reina Sofía, 2011) tienen mayor riesgo de padecer maltrato los niños que presentan problemas de conducta (incluida la hiperactividad), trastornos psicológicos que comportan dificultades en el procesamiento cognitivo (como el trastorno de Asperger y el autismo), problemas de salud, o alguna discapacidad (física, intelectual o sensorial). La prevalencia de maltrato es mayor entre los menores que presentan alguna enfermedad física o trastorno mental $(7,80 \%)$ que entre los que no la presentan (3,57\%).

La mayor vulnerabilidad de los niños y niñas con discapacidad frente a los abusos es, asimismo, respaldada por la Organización Mundial de la Salud, que, a través de su filial WHO-VIP, Violence and Injury Prevention (Jones, 2012), afirma que las personas menores con discapacidad sufren violencia, en todas sus variantes, 
casi cuatro veces más que sus pares sin discapacidad. A la luz de este informe, se observa cómo este concreto colectivo es víctima de una violencia física 3,6 veces mayor y una violencia sexual 2,9 veces mayor que la que sufren los menores sin discapacidad.

Si bien es cierto que, durante el trascurso de la presente investigación, en el ordenamiento jurídico español se encuentra en vías de aprobación la denominada "Ley Rhodes", esto es, la Ley Orgánica de protección a la infancia y la adolescencia frente a la violencia, derivada de la Agenda 2030; y que fue aprobado por el Pleno del Congreso de los Diputados el Proyecto de Ley Orgánica en fecha de 15 de abril de 2021. Esta ley viene a garantizar y ofrecer una mayor protección a los derechos fundamentales de los niños, niñas y adolescentes, su integridad física, psíquica, psicológica y moral frente a cualquier forma de violencia a través de medidas de protección integral, que incluyen la sensibilización, la prevención, la detección precoz, la protección y la reparación del daño en todos los ámbitos en los que se desarrolla su vida (artículo 1).

Se enmarca dentro de los objetivos establecidos en septiembre de 2015 por la ONU en la Agenda 2030 para el desarrollo sostenible. Un plan de acción que los Estados miembros se comprometen a desarrollar en favor de las personas, el planeta y la prosperidad, y que también tiene la intención de fortalecer la paz universal y el acceso a la justicia. La Agenda plantea 17 objetivos con 169 metas de carácter integrado e indivisible que abarcan las esferas económica, social y ambiental.

Como puede observarse, la propia exposición de motivos hace una expresa y específica mención a la especial vulnerabilidad de las niñas. Destacamos de igual modo por su relevancia con el presente estudio, el fortalecimiento y reconocimiento expreso del artículo 3.e) y j) "Reforzar el ejercicio del derecho de los niños, niñas y adolescentes a ser oídos, escuchados y a que sus opiniones sean tenidas en cuenta debidamente en contextos de violencia contra ellos, asegurando su protección y evitando su victimización secundaria.", "garantizar la erradicación y la protección frente a cualquier tipo de discriminación y la superación de los estereotipos de carácter sexista, racista, homofóbico, bifóbico, transfóbico o por razones estéticas, de discapacidad, de enfermedad, de aporofobia o exclusión social o por cualquier otra circunstancia o condición personal, familiar, social o cultural”.

Esta futura ley, aun no solventando la problemática que sufre el específico colectivo de niños, niñas y adolescentes con discapacidad, sí reconoce una mayor protección hacia los menores en general, y a la discapacidad de forma indirecta, salvaguardando sus derechos tanto en sede judicial, como otorgándole asistencia jurídica gratuita y modificando la Ley 15/2015, de 2 de julio, de la jurisdicción voluntaria para asegurar el derecho de los niños, niñas y adolescentes a ser oídos y escuchados en la búsqueda de su interés superior, salvaguardando su derecho a la tutela judicial efectiva, expresarse con libertad y preservando su intimidad.

Aunque, en nuestra opinión, dicha norma velará por los derechos de los niños, niñas y adolescentes con discapacidad, entendemos que, una vez más, lo hace de forma indirecta, siendo necesario, a nuestro juicio, una ley específica que desarrolle la protección de los menores con discapacidad atendiendo debidamente a sus concretas necesidades.

\subsection{Las niñas y mujeres con discapacidad}

En un ejercicio de mayor concreción, las niñas y mujeres jóvenes con discapacidad tienen aún más probabilidad de sufrir violencia que sus iguales sin discapacidad y que los niños y hombres con ella. Es el colectivo 
más vulnerable debido a la concurrencia del género y la discapacidad, pudiendo serlo aún más si concurren otros factores adicionales como la raza o la pobreza, lo que conduce a una discriminación interseccional y múltiple (Cavalcante, 2018, p. 15). Es por ello por lo que la citada interseccionalidad resulta un factor clave que determinará la mayor vulnerabilidad de las niñas y mujeres con discapacidad, en especial por las específicas vulneraciones y tipos de violencia que sobre ellas pueden ejercerse como, por ejemplo, la violencia sexual o la esterilización forzosa.

Y ello, entre otras razones, porque se les niega el derecho a su propia toma de decisiones en relación con su salud reproductiva y sexual, incrementando así el riesgo de violencia sexual, embarazos no deseados e infecciones de transmisión sexual. En esta línea, la ONU reconoció que las mujeres y las niñas con discapacidad suelen estar expuestas a un riesgo mayor, dentro y fuera del hogar, de violencia, lesiones o abuso, abandono o trato negligente, malos tratos o explotación. Aunque las esterilizaciones forzosas constituyen una grave violación de los derechos humanos de las niñas y mujeres con discapacidad, solo recientemente, en concreto, a través de la Ley Orgánica 2/2020, de 16 de diciembre, de modificación del Código Penal para la erradicación de la esterilización forzada o no consentida de personas con discapacidad incapacitadas judicialmente, se ha logrado erradicar esta práctica, permitida en España por el párrafo segundo del art. 156 del Código Penal.

Esta especial vulnerabilidad de las niñas y mujeres con discapacidad tiene su reconociendo internacional en la propia Convención sobre los Derechos de las Personas con Discapacidad, al hacer mención expresa tanto en el preámbulo, letra q), así como dedicándole un artículo, el 6, exclusivamente a este colectivo que sufre la interseccionalidad de factores (así como el artículo 7, en relación con las niñas).

Además de la conjugación de diversos factores que inciden en la mayor vulnerabilidad de las niñas y mujeres con discapacidad, como pueden ser los ya citados de violencia sexual, esterilización forzosa o mutilación genital, existe otro factor que influye y agrava esta interseccionalidad, y es la invisibilidad que sufren en relación con las dificultades que implica la propia discapacidad, y que provoca la mayor indefensión y susceptibilidad de este colectivo, incapaz en muchas ocasiones de expresar o denunciar la violencia que padecen y, en definitiva, hacer valer sus derechos.

En este sentido, para Iniesta y Muñoz (2017), este colectivo se configura como las víctimas más ocultas de la violencia de género puesto que, en numerosas ocasiones, la misma persona que las atiende o se encarga del cuidado que necesitan se convierte en su agresor, quedando expuestas como víctimas en riesgo y factibles de distintas formas de discriminación y violencia de género, y dificultando la denuncia de la víctima.

Algunos de los factores que aumentan el riesgo de desprotección para las niñas y mujeres con discapacidad que sufren violencia pueden ser la dificultad a la hora de defenderse físicamente, la dificultad para expresar los malos tratos debido a problemas de comunicación, la imposibilidad de acceso a los centros de información y asesoramiento principalmente debido a la existencia de todo tipo de barreras físicas y de comunicación, la baja autoestima y menosprecio por la propia imagen como mujer, la mayor dependencia de asistencia y cuidados de otros, el miedo a denunciar el abuso por la posibilidad de la pérdida de los vínculos y la provisión de cuidados, la menor credibilidad a la hora de denunciar hechos de este tipo ante algunos estamentos sociales, etc.

Es por ello por lo que debemos destacar a este grupo de personas en riesgo máximo de vulnerabilidad. Si bien se ha establecido que nuestro colectivo objeto es merecedor de una regulación jurídica autónoma en función de su vulnerabilidad, no es menos cierto que las mujeres con discapacidad suman una serie de 
factores de vulnerabilidad que justifican de igual modo un tratamiento y desarrollo legislativo unitario, independiente del que le ofrece las normas que velan por los derechos de las mujeres, la Convención sobre la eliminación de todas las formas de discriminación contra la mujer (Naciones Unidas, 1979), por ejemplo, o las normativas atinentes a la discapacidad. En un último ejercicio de concreción subjetiva, las niñas, esto es, las menores con discapacidad, que sí estarían inmersas en nuestra investigación, serían el eslabón más vulnerable de la sociedad. Más aún si a la minoría de edad, el género y la discapacidad se le unieran otros factores como la raza o la pobreza.

El $57^{\circ}$ periodo de sesiones de la Comisión de la Condición Jurídica y Social de la Mujer (CSW) tuvo lugar en la Sede de las Naciones Unidas, en Nueva York, del 4 al 15 de marzo de 2013 (Comisión de la condición jurídica y social de la mujer, 2013). Es de suma relevancia para el presente apartado, pues se adoptaron acuerdos en relación a las mujeres y niñas con discapacidad, instando a los Estados a tomar medidas legislativas, administrativas, sociales, educativas y, cualquier índole, a los efectos de proteger y promocionar los derechos de este concreto colectivo de mayor vulnerabilidad, ante cualquier forma de explotación, violencia y abuso.

Propiciado por esta flagrante mayor vulnerabilidad, es por lo que se intenta luchar contra la invisibilidad que afecta y acompaña a las mujeres con discapacidad, quienes ni se consideran objeto de violencia por no ser consideradas en el imaginario colectivo como mujeres plenas (Serrato et al., 2018).

Por ello, puede concluirse que la violencia que se ejerce contra las niñas y mujeres con discapacidad es un fenómeno internacionalmente invisible y oculto, lo que agrava la situación de quienes la sufren, una problemática intuida, lo que dificulta el desarrollo de programas y normativas que luchen para combatirla, al tratarse de una violencia y discriminación existente pero invisibilizada, tanto en términos legales como sociales y estadísticos, que requiere de mecanismos y propuestas legislativas que ahonden en la capacidad de sacar a la luz dicha lacra, y faciliten y pongan a disposición de las víctimas cuantos mecanismos sociales, jurídicos y prácticos sean necesarios para llegar hasta ellos.

El primer paso, a nuestro juicio, para vencer muchos de los problemas que padecen las mujeres y niñas con discapacidad en función a su especial vulnerabilidad pasa por hacerles dueñas de manera efectiva de todos los derechos inherentes a la persona, es decir, no privándoles de muchos de los derechos de los que se ven privadas de forma discriminatoria en razón de su discapacidad, como puede ser la accesibilidad de las mujeres con discapacidad a recursos de información, ayuda o protección en materia de violencia o la sustitución de la capacidad jurídica de las personas con discapacidad, afectando significativamente a las mujeres y posibilitando formas de violencia específicas como la esterilización forzada.

Solo siendo las protagonistas de sus decisiones pueden comenzar a visibilizar las barreras a las que se enfrentan y que agudizan su vulnerabilidad. Solo teniendo pleno poder de ejercicio sobre su capacidad jurídica podrán denunciar la violencia a la que se enfrentan. Solo si promovemos programas y acciones destinados a su accesibilidad, tanto social como judicial, podrán hacer efectivos sus derechos, podrán ser oídas y escuchadas. Solo desarrollando estadísticas sin temor hacia mujeres libres, independientemente de su discapacidad, podremos acercarnos a la realidad de este problema y, juntos, visibilizarlo para poder superarlo y erradicarlo. 


\section{Los factores de riesgo de exclusión de los niños, niñas y adolescentes con discapacidad}

En el día a día de nuestra sociedad son numerosos los casos de marginación a los que se enfrentan las personas menores de edad con discapacidad en distintos ámbitos de la vida como la educación, el acceso a bienes y servicios básicos como la salud o el transporte, el ocio, etc.

En el marco educacional puede encontrarse uno de los factores más discriminatorios y ya no solo por el dato arrollador según el cual tan solo el $2 \%$ de los menores de edad con discapacidad tiene acceso a la educación (Lauzurika et al., 2009), sino porque en España, por lo general, este colectivo se encuentra segregado, separado y apartado del resto de la sociedad, lo que dificulta su plena integración en la sociedad, desobedeciendo lo dispuesto por los tratados internacionales ratificados: de un lado, el art. 23 de la Convención sobre los derechos del niño de 1989, el cual reconoce el derecho del niño con discapacidad ("impedido" dice literalmente, terminología hoy día inadmisible pero hemos de remontarnos a la fecha del tratado) a tener acceso efectivo a la educación y la capacitación con el objeto de lograr su desarrollo individual y su inclusión social; de otro, el art. 24 de la Convención, en el que, de forma explícita, se reconoce a las personas con discapacidad el derecho a la educación, la cual ha de ser inclusiva y de calidad, debiéndose realizar los ajustes razonables que correspondan. En definitiva, las personas con discapacidad no deben quedar excluidas del sistema general de educación por motivos de discapacidad.

En relación con los ajustes razonables citados baste, a los efectos de situarnos en su ámbito general, poner de relieve su definición.

Según el artículo 2 de la Convención, los ajustes razonables son "las modificaciones y adaptaciones necesarias y adecuadas que no impongan una carga desproporcionada o indebida, cuando se requieran en un caso particular, para garantizar a las personas con discapacidad el goce o ejercicio, en igualdad de condiciones con las demás, de todos los derechos humanos y libertades fundamentales".

De igual modo, el Real Decreto Legislativo 1/2013, de 29 de noviembre, por el que se aprueba el Texto Refundido de la Ley General de derechos de las personas con discapacidad y de su inclusión social, la LGD, lo define como "las modificaciones y adaptaciones necesarias y adecuadas del ambiente físico, social y actitudinal a las necesidades específicas de las personas con discapacidad que no impongan una carga desproporcionada o indebida, cuando se requieran en un caso particular de manera eficaz y práctica, para facilitar la accesibilidad y la participación y para garantizar a las personas con discapacidad el goce o ejercicio, en igualdad de condiciones con las demás, de todos los derechos".

Para Carrasquero (2018), los ajustes razonables están estrechamente ligados al concepto de la accesibilidad, entendiéndose esta como la condición que debe cumplir el entorno social a fin de que todas las personas, en condiciones de igualdad, puedan ejercer sus derechos y vivir de manera independiente (Benavides et al., 2008, p. 8).

En este sentido, cabe destacar que, en el trascurso de la elaboración del presente artículo, se ha suscitado un debate legislativo en relación con el marco educacional de los niños, niñas y jóvenes con discapacidad. En este sentido, la denominada "Ley Celáa", la reciente Ley Orgánica 3/2020, de 29 de diciembre, por la que se modifica la Ley Orgánica 2/2006, de 3 de mayo, de Educación, LOMLOE, supone el compromiso de una mayor inclusión para las niños, niñas y jóvenes con discapacidad en centros de educación ordinaria, 
salvo aquellos que requieran atención muy especializada, y una mayor dotación de recursos para la atención del alumnado con discapacidad en los centros educativos, no renunciando a la inclusión de los mismos en igualdad de condiciones que el resto de sus pares sin discapacidad en el acceso a una educación de calidad.

Ya en su preámbulo destaca el respeto a las diferencias individuales, y el objetivo de promover la solidaridad y evitar la discriminación, con el fin de lograr la necesaria cohesión social y una escolarización equitativa del alumnado, reconociendo el interés superior del menor, su derecho a la educación y la obligación que tiene el Estado de asegurar el cumplimiento efectivo de sus derechos, especialmente, el derecho de aquellas personas en situación de mayor vulnerabilidad, a la educación inclusiva como derecho humano para todas las personas, reconocido en la Convención.

Vuelve a hacer referencia a los ajustes razonables en materia de educación en el propio preámbulo de la citada Ley, asegurándolos en función de las necesidades individuales y prestando el apoyo necesario para fomentar el máximo desarrollo educativo y social, de manera que todos los niños, independientemente de su discapacidad - no hace referencia a este término en el preámbulo- puedan acceder a una educación inclusiva, en igualdad de condiciones con los demás.

Así, podemos observar cómo el propio artículo 1 hace referencia expresa a los conceptos de interés superior del menor, derecho a la educación, a no ser discriminado y expresamente en los epígrafes 1.1.a) bis y 1.1.b) de este primer artículo se determina la no discriminación por razón de discapacidad, la educación inclusiva y la accesibilidad. De igual modo el artículo 3.3, estableciendo como principio fundamental la educación inclusiva, así como referencias expresas al alumnado con discapacidad en artículos como el 9.3, el 14.3, 25.c), 38.5, y muy especialmente el desarrollo extenso del artículo 49 y 50, que establecen los parámetros a seguir para conseguir el objetivo de una educación inclusiva para la infancia con discapacidad, teniendo en cuenta el interés superior del menor y la voluntad de las familias que prefieran el régimen ordinario, revisiones periódicas y plan para que los centros ordinarios cuenten con los recursos necesarios para poder atender al alumnado que se enfrente a barreras y dificultades en su aprendizaje.

Como se ha indicado, se trata de una reforma sobre una materia que ha sido objeto de debate en los últimos años y que tiene un amplio desarrollo jurisprudencial, justificando, por tanto, la necesidad de su revisión legislativa. En este sentido, podemos destacar algunas sentencias como la Sentencia del Tribunal Superior de Justicia de Andalucía, Málaga (Sala de lo Contencioso-Administrativo, Sección $3^{a}$ ), Sentencia núm. 1385/2017 de 10 julio, en la que se estima el recurso interpuesto por la representación de un alumno con discapacidad que no fue admitido en la matriculación de formación profesional a razón de su edad, sin tener en cuenta los ajustes razonables que deben modificar este límite para las personas con necesidades especiales, declarando el derecho del actor a la escolarización.

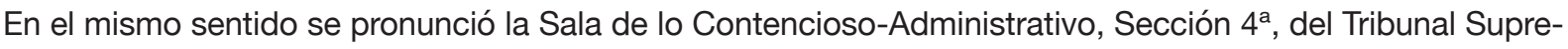
mo, mediante Sentencia 1976/2017 de 14 diciembre, en la cual se reconoció el derecho de un menor a seguir escolarizado en un centro ordinario, frente al criterio de la Consejería de Educación, que autorizó el cambio de modalidad de escolarización al alumno con necesidades educativas especiales, confirmándose por el Alto Tribunal que dicha resolución menoscababa el derecho a la igualdad, reconocido en el artículo 14 de la Constitución Española, en relación con el artículo 27 de la misma, en el ejercicio del derecho a la educación, siendo preceptivos unos informes profesionales, teniendo en cuenta las peculiaridades de cada caso y razonando la carga desproporcionada que justifique sin género de dudas la necesidad del cambio, lo cual no se acreditó en la citada sentencia. 
En este sentido, España es objeto, a día de hoy, de observación en relación con la protección efectiva de los derechos de las personas menores de edad con discapacidad. Como ya tuvimos ocasión de ver, el Comité sobre los derechos de las personas con discapacidad de la ONU realizó en 2017 un informe de conclusiones sobre la vulneración del derecho a la educación de menores con discapacidad, con especial atención al cumplimiento efectivo de las directrices impuestas a los Estados Parte en la Convención (Comité sobre los derechos de las personas con discapacidad, 2017). Entre las conclusiones más destacadas, se indicó que en España no existe un efectivo reconocimiento generalizado del modelo de derechos humanos de las personas con discapacidad, detectando una flagrante falta de acceso a la educación inclusiva y de calidad para este colectivo. Además, consideró insuficientes las medidas adoptadas para promover esta educación inclusiva y una falta de claridad a la hora de aplicarla por las autoridades. Por ello, realizó una serie de recomendaciones en esta materia a los efectos de su cumplimiento en España. Entre ellas, destacó la eliminación de la educación segregada, la contemplación de la educación inclusiva como un derecho, y no como un principio, y la inclusión de una cláusula de no rechazo por causas de discapacidad, lo cual se considera discriminatorio para este colectivo.

Como ya se ha señalado, existe una serie de factores de riesgo que aumentan la vulnerabilidad de los niños, niñas y adolescentes con discapacidad: el estigma social, la discriminación ya comentada, el desconocimiento de la discapacidad, la falta de apoyo hacia las personas cuidadoras, etc. Ello puede derivar, en muchos casos, en una mayor probabilidad para ser víctima del maltrato infantil o de la marginación social y exclusión.

En este sentido, para Berástegui y Gómez-Bengoechea (2006) hay algunas cuestiones asociadas a la propia discapacidad que aumentan el riesgo de sufrir episodios de maltrato, dificultan el reconocimiento de los mismos por parte del menor, o dificultan que el menor pueda defenderse inmediatamente frente al maltrato o denunciarlo posteriormente.

En la actualidad, existen otros factores más que pueden incrementar la vulnerabilidad de los menores de edad con discapacidad. Causas como las enfermedades, desnutrición, guerras, descuido de la higiene o la pobreza, son factores que aumentan la fragilidad de estos sujetos ya de por sí vulnerables, derivando en consecuencias trágicas contra la propia vida de estos seres indefensos, a las que se suma la absoluta desprotección jurídica ante la conculcación de sus derechos humanos.

Especial relevancia tiene el factor de vivir en países en vías de desarrollo, lo cual provoca un mayor número de barreras (Cutillas, 2017) y, por consiguiente, una tasa más alta de personas con diversidad funcional respecto a los países desarrollados. La pobreza, la violencia, las enfermedades, la falta de atención y medios sanitarios, la inaccesibilidad de las infraestructuras y un largo etcétera, ocasionan que los niños y niñas que viven en estos territorios más desfavorecidos tengan mayores dificultades para acceder a recursos esenciales para atender sus necesidades, lo que contribuye a su mayor vulnerabilidad y exclusión (Barnes, 2010).

La pobreza y la discapacidad están estrechamente ligadas o interrelacionadas, ya que la pobreza es una causa muy importante de la discapacidad y esta conduce en muchos casos a la pobreza. En esta línea, para Martínez-Ríos (2011) la vulneración de los derechos de las personas con discapacidad genera costes extraordinarios, que conducen, a su vez, a situaciones de pobreza. Visto desde el otro ángulo, cuando estos costes extraordinarios no son cubiertos generan una pérdida de derechos para este colectivo, colocándolo en una situación de desventaja y desigualdad (Martínez-Ríos, 2013). 
Sobre el papel los Estados partes de la ONU deben garantizar los derechos de las personas con discapacidad sin discriminación, incluyendo el acceso a alimentos, agua limpia, ropa y servicios, como así se establece en la Convención, si bien esto no se cumple en la mayoría de los países en vías de desarrollo, originando esa dualidad entre pobreza y discapacidad.

Especial referencia debe hacerse a la niña o adolescente con discapacidad en estos países en desarrollo, donde sus derechos son especialmente conculcados al enfrentarse a mayores abusos sexuales, esterilizaciones, abortos y contagios de enfermedades venéreas.

Así las cosas, a la vulnerabilidad propia del colectivo de menores con discapacidad en razón de la edad y de su deficiencia, se suman las diferencias sociales, culturales y económicas de los distintos países, lo que provoca la indefensión interseccional de otros factores y la absoluta desprotección jurídica de este grupo de personas. Por ello, desde el derecho internacional debe prestarse una especial atención a la protección jurídica de los derechos de los menores de edad con discapacidad, en tanto se configuran como el colectivo de sujetos de derecho más vulnerable de la sociedad. El reconocimiento de esta mayor vulnerabilidad, así como su identificación como un colectivo específico dentro de los grupos vulnerables y la necesidad de su mayor protección jurídica, constituyen los objetivos del presente artículo.

Consideramos que ello es crucial para la prevención y detección temprana de las distintas formas de abuso y violencia que hoy día sufren. Para ello, no basta con que los Estados ratifiquen la Convención de los derechos del niño, así como la Convención, sino que han de promover leyes, políticas y acciones centradas en la tutela de los derechos de los menores con discapacidad. En este sentido, han de llevarse a cabo programas de prevención de la violencia sobre los niños y niñas con discapacidad, es preciso acabar con su institucionalización de manera segregada de la sociedad, deben suprimirse las barreras de toda índole a la inclusión, han de arbitrarse medidas de apoyo a las familias y a los cuidadores y ha de incorporarse a los menores de edad con discapacidad en la toma de decisiones que les afectan, no solo como beneficiarios, sino como protagonistas de las mismas para, de este modo, conseguir una participación en la sociedad plena e igualitaria. Para ello es esencial la concienciación social sobre lo diverso.

\section{Conclusiones}

En definitiva, a la vulneración provocada por la propia discapacidad del sujeto menor con discapacidad se incorpora la indefensión interseccional de otros factores sociales, provocando la absoluta desprotección jurídica de este grupo de personas. Por ello, entendemos que es necesaria la armonización y desarrollo de las políticas que conducen a la correcta integración práctica de los principios y recomendaciones establecidos por la ONU en todos los Estados miembros en materia de protección jurídica de los derechos de los niños, niñas y jóvenes con discapacidad, en especial, en aquellos países en vías de desarrollo en los cuales a la propia discapacidad se le unen los obstáculos y dificultades derivados de la falta de mecanismos y medios de asistencia.

De todo ello se desprende que, desde el derecho internacional, así como desde los distintos Estados, debe prestarse una especial atención en la protección jurídica de los derechos de los menores de edad con disca- 
pacidad, en tanto se configuran como el colectivo de sujetos de derecho más vulnerable de la sociedad, diferenciándose en cuanto a fragilidad e indefensión a los demás grupos de especial debilidad por las propias circunstancias y condiciones de estos sujetos. El reconocimiento de esta mayor vulnerabilidad, objetivo que pretendemos en el presente artículo, así como su identificación unitaria como sujetos de derechos individualizados de los demás grupos vulnerables, conducirá a una protección mayor y, a nuestro juicio, establecería el primer paso para la prevención y detección temprana y eficaz de las distintas marginaciones, abusos o violencia que sufren.

Con el objetivo de garantizar el cumplimiento de los derechos humanos reconocidos por las convenciones internacionales a las niñas, niños y jóvenes con discapacidad, y con el fin de prevenir y evitar las situaciones discriminatorias a las que se enfrentan a diferencia de otros grupos vulnerables, los Estados deberán, en nuestra opinión, no solo ratificar la Convención de los derechos del niño y la Convención sobre los derechos de las personas con discapacidad íntegramente sino promover, a través de leyes específicas y acciones sociales, la lucha contra esta discriminación.

De este modo, se promovería la concienciación social sobre la discapacidad, la aplicación de manera prioritaria y punitiva de los programas de prevención para la violencia infantil, con especial dedicación respecto a los menores con discapacidad, desincentivar y acabar con la institucionalización de los menores de edad con discapacidad en centros apartados de la sociedad, eliminar barreras a la inclusión, apoyar a las familias y cuidadores, promover programas de investigación sobre la discapacidad y sobre todo, incorporar a los menores de edad con discapacidad en la toma de decisiones que les afectan, no solo como beneficiarios, sino como protagonistas para el cambio, consiguiendo que logren una participación en la sociedad que sea plena e igualitaria.

Solo de este modo entendemos que se podrá progresar en la equiparación de derechos y oportunidades de este colectivo con el resto de la sociedad. 
Referencias bibliográficas

Arévalo, E. J. (2015). La protección jurídica a las personas en situación de vulnerabilidad y el respeto a la autonomía de la voluntad. Revista IUS, 9(36), p. 61-88.

Barnes, C. (2010). Discapacidad, política y pobreza en el contexto del Mundo Mayoritario. Política y Sociedad, 47(1), pp. 11-25.

Benavides, A. et al. (2008). Informe sobre pruebas de acceso al empleo público de las personas con discapacidad. Instituto de Derechos Humanos Bartolomé de las Casas.

Berástegui, A. y Gómez-Bengoechea, B. (2006). Los menores con discapacidad como víctimas de maltrato infantil: una revisión. Psychosocial Intervention, 15(3), pp. 293-306.

Bobbio, N. (1991). El tiempo de los derechos. Sistema.

Carrasquero, M. (2018). Los ajustes razonables para personas con discapacidad en la Unión Europea. Revista de Estudios Europeos, (71), pp. 38-47.

Castaño, M. J. et al. (2019). Informe. Colectivos vulnerables en el sistema de asilo. Una aproximación a las necesidades de la infancia, personas LGTBI+ y víctimas de trata. Instituto Universitario de Estudios sobre Migraciones de la Universidad de Comillas.

Cavalcante, A. M. (2018). Discriminación interseccional: concepto y consecuencias en la incidencia de violencia sexual contra mujeres con discapacidad. Journal of Feminist, Gender and Women Studies, (7), pp. 15-25.

Centro Reina Sofía (2011). Informe del Centro Reina Sofía sobre el maltrato infantil en la familia en España. Ministerio de Sanidad, Política Social e Igualdad. https://observatoriodelainfancia.vpsocial.gob.es/productos/pdf/ malt2011v4_total_100_acces.pdf.

Comisión de la condición jurídica y social de la mujer (2013). Informe sobre el 57 período de sesiones (4 a 15 de marzo de 2013). Consejo Económico y Social. Naciones Unidas. https://undocs.org/pdf?symbol=es/E/2013/27.

Comisión Europea (2010). Estrategia Europea sobre Discapacidad 2010-2020: un compromiso renovado para una Europa sin barreras. Comisión Europea. https://www.mscbs.gob.es/ssi/discapacidad/docs/estrategia_europea_discapacidad_2010_2020.pdf.

Comité de los derechos del niño (2007). Observación General nº 9 (2006). Los derechos de los niños con discapacidad. Naciones Unidas. https://bit.ly/3yYEv8v.

Comité sobre los derechos de las personas con discapacidad (2016). Observación general núm. 3 (2016), sobre las mujeres y las niñas con discapacidad. Naciones Unidas. https://bit.ly/3poJYkl.

Comité sobre los derechos de las personas con discapacidad (2017). Informe de la investigación relacionada con España bajo el art. 6 del Protocolo Facultativo. Naciones Unidas.

Cutillas, E. (2017). Distribución mundial de la población con discapacidades en relación con los patrones geográficos del desarrollo humano. Documents d'Anàlisi Geogràfica, 63(1), pp. 29-53.

España (2021). Proyecto de Ley Orgánica de protección integral a la infancia y la adolescencia frente a la violencia. Boletín Oficial de las Cortes Generales, 14 de abril de 2021, núm. 22-4, pp. 1-68. https://www.congreso.es/ public_oficiales/L14/CONG/BOCG/A/BOCG-14-A-22-4.PDF. 
Eurostat (2013). Guía de la estadística en la cooperación al desarrollo de la Comisión Europea. Eurostat. https:// ec.europa.eu/eurostat/documents/3859598/5926561/KS-RA-13-002-ES.PDF/c0174f3d-c08c-4f26-aa80bf5ee6678eb3.

Gosálbez, M. B. (2013). Estadísticas de discapacidad: estado de situación, necesidad y perspectivas. Economía Española y Protección Social, (5), pp. 169-202.

Iniesta, A. y Muñoz, P. (2017). Invisibilidad de la violencia de género en mujeres con diversidad funcional. International Journal of Developmental and Educational Psychology, 4(1), pp. 195-202.

Jones, L. (2012). Prevalence and risk of violence against children with disabilities: A systematic review and meta-analysis of observational studies. The Lancet, 380(9845), pp. 899-907.

Lauzurika A. et al. (2009). El derecho a la educación de las personas con discapacidad. Una aproximación desde América Latina en los últimos 15 años. En M. R. Berruezo (Coord.), El largo camino hacia una educación inclusiva: la educación especial y social del siglo XIX a nuestros días: XV Coloquio de Historia de la Educación (pp. 147-160). Universidad Pública de Navarra.

Lázaro, I. (2014). Cuadernos para el debate: vulnerabilidad y exclusión en la infancia, hacia un sistema de información temprana sobre la infancia en exclusión. Huygens.

Martínez-Ríos, B. (2011). La discapacidad y la pobreza desde las principales teorías de desarrollo. En B. MartínezRíos, Pobreza, discapacidad y derechos humanos (p. 67-155). Cinca.

Martínez-Ríos, B. (2013). Pobreza, discapacidad y derechos humanos. Revista Española de Discapacidad, 1(1), pp. 9-32.

Miñarro M. (2017). La protección socio-laboral de los refugiados como grupo vulnerable: balance crítico y propuestas de mejora. Nueva Revista Española de Derecho del Trabajo, (203), pp. 223-247.

Naciones Unidas (1979). Convención sobre la eliminación de todas las formas de discriminación contra la mujer. Naciones Unidas.

Naciones Unidas (1989). Convención sobre los derechos del niño. Naciones Unidas.

Naciones Unidas (2006). Convención sobre los derechos de las personas con discapacidad. Naciones Unidas.

Peces-Barba, G. (1991). Curso de derechos fundamentales. Teoría General. Eudema.

Serrato M. et al. (2018). Violencias contra mujeres: la incansable lucha por ser visibles. Revista Latinoamericana en Discapacidad, Sociedad y Derechos Humanos, 2(2), pp. 132-145.

Unicef (2013). Niños, niñas y jóvenes con discapacidad. Hoja informativa. Unicef. https://sites.unicef.org/disabilities/files/Factsheet_A5-o_spanish-r4.pdf. 